\title{
Perception of employers and employees regarding the attitude of businesses toward the environment: A qualitative analysis
}

\author{
María José García-López ${ }^{1 \star}$, Carmen Avilés-Palacios ${ }^{2}$ and Manuel López-Quero² \\ ${ }^{1}$ Facultad de Ciencias Jurídicas y Sociales, Universidad Rey Juan Carlos, Paseo de Artilleros s/n, \\ 28032 Madrid, Spain. \\ ${ }^{2}$ ETSI Montes, Universidad Politécnica de Madrid, Ciudad Universitaria s/n, 28040 Madrid, Spain.
}

Accepted 17 October, 2011

\begin{abstract}
Commitment and involvement from the different members of an organization are two key elements for an organization to achieve its environmental excellence. Firstly, businesses are aware of the close relationship between their activities and the environment, for they are not only polluting agents but also agents with the capacity to reduce adverse environmental impacts. Secondly, the fact that employees can play a relevant role in terms of the socially responsible measures to be taken by organizations has started to become an irrefutably important issue. This piece of research is intended to help gain knowledge concerning the attitude of the two main actors in productive activity toward the environmental, that is, employers and employees; as well, this research intends to identify factors determining behaviour towards the environmental. For this, we have gathered the ideas and assessments contained in the discourse of a group of small and medium-sized businesses, large company owners and officers, employees, and work related risk prevention representatives. Qualitative work consisted of in-depth interviews and the creation of discussion groups.
\end{abstract}

Key words: Employees, employers, environmental responsibility, preventive culture, environmental management systems.

\section{INTRODUCTION}

Serious and accumulative environmental damage, the environmental disasters of recent years caused principally by spillage from business organizations and the irresponsible use of natural resources, led us to reexamine the basic concept of industrial growth and to consider the environmental variable as a fundamental economic factor. Years ago, the environmental excellence of companies was an intangible asset, the

${ }^{*}$ Corresponding author. E-mail: mariajose.garcia@urjc.es. Tel: +34670994532 . perception of which was difficult for the interest groups concerned with it. Little by little, however, society has become concerned about environmental issues and businesses are required with ever-greater pressure to respect the environment in which their activities are developed. In turn, business competition exercises an increasingly stronger pressure on companies. Management of social, ethical and environmental impact related to the action of companies is becoming genuine imperative to the extent that the environmental image of a company becomes an asset or a liability assessed by investors, insurers, clients, suppliers and users in generals. 
For this reason, many companies within all sectors of the economy have begun to realize that their attitude towards the environment has acquired the nature of a decision with far-reaching implications so far as the economic, political and social environment that has gradually taken shape in recent years has turned the environmental issue into an important strategic factor, conditioning not only the capacity of a company to create value for its shareholders, but also its ability to manage the risks surrounding that capacity. Consequently, taking decisions with regard to the environmental performance of a company does not differ significantly from the decision procedures any organization is confronted with. It is increasingly evident that the impact of businesses on the environment can lead to risks that, in turn, can have significant impact on their economic and financial performance.

Companies are increasingly aware of the close relationship between their activities and the environment, since they are, the major polluting agents, and on the other hand, they have the capacity to reduce adverse environmental impact. The gradual increase in environmental awareness in society forged principally towards the end of the 1970s, demands that public authorities address the responsibility of companies causing serious environmental impacts. It is for this reason, that companies have started to take measures to internalize the external effect their activities have.

\section{EMPLOYERS AND EMPLOYEES: TWO CLOSELY INVOLVED AGENTS}

The environmental strategy adopted by companies can cover several proactive levels. The environmental measures taken by companies respond basically to two different types of forces. Firstly, measures arise from new environmental policies (both national and European, as well as worldwide). In this respect, at the international level: the United Nations Conference on the Environment, held in Stockholm in 1972; the report drafted in 1987 by the World Commission for the Environment, where the concept of sustainable development was created; the European Union Environment Action programmes; the Kyoto Protocol, etc. This trend in international policy, and Spain's joining the European Union when three Community Action Programmes had already started, meant that Community regulations had to be incorporated into the Spanish legislation (Fuentes, 1995).

Secondly, there are several theories about how organizations respond to the pressure exercised by certain groups considered direct participants in a company's interests.

The Stakeholder theory assumes, that organizations adopt environmental management practices in order to align their strategies with environmental regulations and beliefs, and in this way, acquires social legitimacy to the point to which they achieve socially accepted objectives. According to this approach, coming closer into line with the environmental demands of these groups reflects a moral commitment that seeks social recognition through the adoption of responsible environmental measures (Freeman, 1984; Shrivastava, 1994; Madsen and Ulhoi, 2001; Bansal and Roth, 2000).

Considering employees as relevant subjects in the productive activity is certainly indisputable (Talentito, 2000; Fashion, 2000). Nevertheless, the relevance of the role that employees can play in the environmentally responsible measures taken by organizations is also starting to be seen as irrefutable (Olano and Ferrer, 2006). The different proposals necessary for an environmental management system to be successfully implemented, as well as the Green Paper on Social Responsibility, stress how important it is to achieve commitment by senior management and to create an organization and a culture that enable each individual person to help reach environmental excellence.

A number of factors that will condition the employees' commitment towards the true assumption of a company's social responsibility, as well as towards taking measures intended to improve the environmental behaviour of the company were examined. Moreover, these aspects helped to define the objectives pursued in this paper.

Firstly, business culture is a complex phenomenon. The beliefs of organizations (one of the elements defining business culture) are made up of the set of truths shared by the organization's members and used by these members to comprehend and to act upon internal and external realities (Martínez and Lucas, 2002). It must be borne in mind that business organizations integrate minor organizations that, though sharing the common business culture have cultures of their own denominated sub-cultures. For business culture to operate in the interest of an organization and not to hamper the path taken by the organization, the beliefs of the company as a whole and those held by the subgroups must necessarily be harmonized and work in a coherent and consistent fashion (Llorente, 2004).

This explains why, when it comes to the implementation of environmental management systems, it is important to achieve a commitment by management and stimulate and motivate the other people who are part of a company. Commitment by senior management provides a framework without which it is not possible to motivate employees. This commitment must not only exist, it must be properly transmitted to employees. Successful performance of an environmental management system depends on good internal communication, since success can be achieved only if all employees understand their roles and have motivation to participate fully (Hunt and Johnson, 2000). Objectives and priorities must be properly communicated and a participatory culture adopted (Govindarajulu y Daily, 2004). 
Communication makes it possible for everyone to realize how important it is to adopt preventive pollution strategies, as well as the relevant role each individual can play. Employees in different departments should perceive how important and valuable the other employees are, that is, the production staff knows the process; environmental staff, the environmental priorities; lawyers, the legal requirements; etc. (Hoffman, 1993). In some cases, workers, together with engineers, can decide on important solutions. The former know where the opportunities are, though they often don't have the necessary technical training to find a solution.

We also emphasize the importance of a participatory culture because the level of commitment by, and awareness of, employees is higher when individuals are given the opportunity to join in the decision-taking process (Theyel, 2000). We understand that adapting companies to the legal and technological requirements that can fulfil the new environmental demands made by society requires the active participation of employees and their representatives in the design of new sustainability policies and in the implementation of environmental management systems.

In 1996, the Optimum Programme studies tried to gain an insight into the opinion held by employees of large companies within the capital goods, iron and steel, and food industries. And the ESP-funded FITTEMA Programme (Research and Transfer of Environmental Technology and Employment) covered several studies aimed at getting information on the relationship between environmental protection and job creation, and the possibility of clean technologies being implemented in Spanish industry and agriculture.

Despite the studies referred to above, not much research has been done to find out what factors make companies take certain environmental measures. With the overall purpose of gaining further insight into the environmental attitude of the two main actors in the productive activity and of helping to identify factors that determine the environmental behaviour of businesses, the following objectives are framed within the context of this study:

1. Determining the attitude and extent of awareness of employees and employers in relation to the protection of the environment, within the scope of their productive, economic and labour activity.

2. Learning about how the people interviewed, perceive the image that different social agents have of the company.

3. dentifying the detected barriers and opportunities for the introduction of preventive measures.

4. Analysing how employers and employees perceive the potential adverse environmental impacts caused by their business activity, the efficiency of implementing initiatives for environmental improvement, the development of environmental management systems, and the degree of business compliance with environmental regulations.

5. Becoming familiar with the development of environmental training and informative activities.

6. Diagnosing the extent of participation by employees and their legal representatives in the design and performance of environmental policies. Understanding how trade union representatives assess their own work in this respect.

\section{MATERIALS AND METHODS}

In order to achieve the objectives specified in the section above, we applied a qualitative method that enables us to detect, disclose and express the structural representation of subjects and/or groups formed by the subjects according to different variables. We are aware of the limitations of this type of research, which will not make it possible for us to formulate generally applicable theories in the matter. Nonetheless, the qualitative research approach starts with the following idea: the structural position in which individuals or groups are found or placed, at the micro level in organizations and at the macro level in the social organization, determines how they create their perceptions, attitudes, decisions, actions and discourse. Information obtained through qualitative research enables us to detect and define, through the subjects' discourse, the issues that are socially associated with the purpose under study. Discourse analysis enables us to obtain information that can bring us closer to the knowledge and understanding of the different social representations targeted by our study, making it possible to include and comprehend those representations within the ideological framework in which they are found. Our work focuses on the knowledge of ideas and assessments as expressed by a group of business owners and officers, employees, and work related risk prevention representatives, in small and mediumsized companies as well as large enterprises.

Qualitative work consisted of carrying out in-depth interviews and creating discussion groups. These two approaches were employed to gain an insight into the world of ideological representations co-existing in Spanish businesses vis-à-vis the environmental issue, specifically in terms of the relationship between business activity and environmental damage or protection. As stated above, two different techniques were applied to obtain information for our study: in-depth interviews and discussion groups.

\section{Technical data on in-depth interviews}

The sampling of in-depth interviews cover industrial companies in Madrid, particularly companies related to cement, petrochemical and construction activities. The scope is based in the Autonomous Region of Madrid as it is thought that this region is sufficiently representative from the business activity standpoint. A wide range of companies from within different polluting industries is found in the region. They either develop their activities within the region or they have their headquarters there.

Six in-depth interviews were carried out with the people responsible for environmental matters in the selected companies. Table 1 shows the information on interview segmentation. It must be taken into account that for two of the four large companies studied in the sample, the consultancy firms responsible for environmental matters were interviewed. In the case of small companies, the managers were interviewed since they were the ones responsible for environmental matters (Table 1).

The interviews lasted from $45 \mathrm{~min}$ to one hour and thirty minutes. The interview plan used was developed by RANDOM on 
Table 1. Interview segmentation.

\begin{tabular}{lccccc}
\hline Activity area & Cement & Petrochemical & Construction & Textile & Footwear \\
\hline Size & & & & & \\
Small company & & & 2 & 1 & 1 \\
Large company & 1 & 1 & & \\
\hline
\end{tabular}

the basis of the objectives pursued by this study.

\section{Technical data on the discussion groups}

As for the companies selected for the discussion groups, both territorial and industrial aspects were considered. Companies from polluting industries were selected: four companies from the Autonomous Region of Madrid, chosen on the grounds given above, and companies from Andalucia, since this Autonomous Region is eligible for subsidies under objective number 1 of the European Union's regional policy. Four discussion groups were created. For this, 17 companies from the chemical industry were contacted in Andalucia; 19 companies from the iron and steel industry (in the same Autonomous Region); 15 companies from the chemical industry in Madrid; and 16 from the service sector in Madrid. Annex I contains technical data on each discussion group.

\section{RESULTS OF IN-DEPTH INTERVIEWS AND DISCUSSION GROUPS}

\section{Perceptions regarding the level of environmental awareness}

The trend in environmental awareness in Spanish companies was the first issue discussed in the interviews with the people responsible for environmental matters in the companies targeted for study.

\section{Employers}

The analysis of the in-depth interviews shows that there appears to be consensus in the group of employers surveyed in that they all believe that the level of environmental awareness has gradually increased in recent years, particularly from the 1990s on.

The general opinion of those interviewed is that this advance appears to be the result of a number of interacting factors. These factors can be summed up as follows: advances in work related risk prevention and occupational safety matters; the behaviour of large companies; and the development of legislation and government assistance and subsidies. Although the advances in work risk prevention and occupational safety matters appear to be the driving factor behind increased environmental awareness, this factor conditions, and is conditioned by, the other two: large companies, forced by the development of environmental and work related risk prevention legislation, and helped by government subsidies, have taken the lead in the development of environmental projects, which is another key factor in the rise in environmental awareness.

The fact that large companies have made more progress than small companies appears to be due to the fact that the environmental risks of large companies are higher than those of small and medium-sized companies. This, together with the pressure from the government, has stimulated behaviour which, to a greater or lesser extent, has pushed the advances in environmental matters. Finally, mention must be made of the importance of the development of legislation and subsidies. It appears that this factor (considered from both sides: subsidies and fines) has helped and/or forced companies to get involved.

From the interviews with the representatives for the companies, we can conclude that the development of legislation and more subsidies, the advances in work related risk prevention, and the role of the large company as a catalyst all emerge as the primary elements triggering the rise in environmental awareness. Yet, there are other factors that have favoured the environmental commitment of companies, which we will discuss below.

\section{Employees}

In the past ten years, the general trend shows increased awareness of the importance of the problems in environmental protection, as well as the consolidation of a positive attitude towards the same. Yet, the issue is still dealt with as something new, and several participants in this study believe that companies are not taking sufficient measures to address the environmental problems they create and reduce their impact on the environment.

According to the employees interviewed, some companies take environmental problems into as much consideration as work related risk prevention, if not more. However, they do not think that environmental actions as developed by companies result from their strict conviction that the environment must be protected. The employees interviewed also believe that employees as a whole are not sufficiently aware of the environmental issue, although they feel that the companies where they work are implementing significant measures for awareness creation.

Employees are aware that a great many companies use and generate polluting products and waste. The 
general perception is that, though measures are beginning to be taken with regard to the environmental impact of productive activities, there is still a great lack of protection, particularly in industries where processes are highly polluting. The employees believe that it is very difficult to achieve integral control of waste or pollutant disposal. Most of them, however, think that companies try to monitor dangerous processes as far as this is possible, and they trust it. This explains why some employees who participated tend to minimize the environmental damage caused by their companies, making reference to recent measures and offering exculpatory or sympathetic comments on the basis that it is not always easy to prevent or overcome certain situations.

At times, the employees interviewed assert that they still do not know the level of environmental risk and danger posed by some products and processes. To a large extent, this is due to disinformation on the part of the company, and in other cases to an overall absence of social information. However, the general trend is that employees know the poisonous and hazardous products which they use, and the risks involved for their own health and the environment since companies have implemented significant work related risk prevention programmes.

All the participants in the different discussion groups recognize the polluting processes of their companies, from emissions to waste generation, from dumping to noise pollution. They recognize the risk of using certain hazardous products and substances and of not monitoring the processes in which they are used; and they point out that companies sometimes try to hide these situations.

Employees from small companies show consensus that large companies are the ones that pollute the most and, consequently, that they are the ones that must take measures. Although their companies use poisonous and polluting products, they think that their activities and processes are not particularly harmful to the environment.

In large companies, the view of employees toward the environmental impact of the activity in which they take part is not only restricted to what happens inside the plants. They also know what happens with their products afterwards.

In the course of the discussion, the participants compare different processes and activities, and identify which are most problematic. This is interesting when it comes to analysing their perceptions of danger, given the fact that, generally speaking, they all feel quite safe when handling polluting products or when involved in polluting processes. Most of them are of the opinion that consumption levels are still high and, as a result, environmental impact and costs remain high. This is so despite efforts made by company managers, driven by economic motives, to take measures to improve efficiency in the use of water, energy, and raw materials. Employees are well aware of the issue, particularly employees of small and medium-sized companies where there is likely to be more delay and difficulty in implementing changes and innovations to improve consumption levels.

\section{Corporate image of companies}

\section{Employers}

The importance of corporate image appears to be the main reason for large companies to change their business philosophy. The relationships among management, shareholders, and users/clients, and the role played by the mass media in that relationship, appear as the main reasons for the change. Moreover, the growing demand by clients is passed on to the supply chain, another factor that emerges as an additional factor driving large companies towards environmental commitment.

\section{Employees}

The perception of the employees participating in our discussion groups is that the companies whose end product is a brand-name product, as is the case with cars, or aircraft in the iron and steel industry, are indeed concerned about their environmental image. In fact, they look at it as one more marketing strategy. Other companies are satisfied with not generating adverse publicity.

On the other hand, according to the employees interviewed, companies in the chemical industry make a great effort to maintain a public image of deep respect towards the environment, even though they may not be so careful about what goes on inside their plants. The utmost care is often taken so that possible non-compliance with environmental regulations is not perceived from the outside. Along these lines, green surroundings and glass buildings have been used so that plants look modern, bright, and colourful. In general, employees appreciate the attempts made by companies to improve their environmental image, but they are sceptical about the results.

\section{Factors that promote the environmental commitment of companies}

\section{Employers}

Apart from corporate image and demands by clients (the main reasons driving companies to undertake environmental commitments), a number of factors can be appreciated that help encourage small, mediumsized, and large companies to undertake environmental commitments. For instance, there is growing awareness among citizens, which is prompting them, in their multi- 
faceted role as consumers, clients, and business agents, to form a new lobby that demands greater environmental commitment from companies. As well, there is the existing legislation and its future development, which obliges and enables companies to address the growing social demands in environmental matters.

\section{Employees}

The majority of employees believe that the main factors driving companies to commit to environmental causes are the generation of laws and the strict application of regulations concerning environmental protection. For the employees, one of the factors underlying a company's commitment, when it comes to taking environmental measures, is that companies fear being penalized and fined by the government, which could lead to a company closing down. Consequently, control and inspection by the government is thought to be essential. In the case of multinationals, what the parent company dictates is complied with at the national level; that is, the commitment comes from senior corporate management, so there is a greater degree of perception by employees regarding environmental commitment.

Financial savings are also mentioned as a factor encouraging environmental commitment. The fact that products can be cheaper while at the same time more environmentally friendly is perceived as a factor that might encourage both users and employers to undertake environmental commitments. Another important factor is the commitment by governments to improve recycling infrastructures and to organize existing resources in order to make it easier for companies to improve their environmental management.

As a factor leading companies toward environmental commitments, the employees point out the attempt by companies to show a good image vis-à-vis third parties, particularly companies whose end product is a brandname product (this was discussed in section 4.2 on corporate image). However, at this point, employees differentiate between large and small companies. According to the employees, large companies have more reasons to take care of the environment: economic reasons, pressure from trade unions, trademark image, impact on the media, etc. The impact of actions by small companies on their image is much less. Some participants explain further that concern about corporate image does not depend so much on whether a company is large or small, rather on the industry where the company is found. According to our participants, a company in the service sector will undoubtedly be more concerned about its image.

Finally, as another factor encouraging companies and therefore their employees to undertake environmental commitments, they point out a system whereby employees receive an extra annual payment only if the company succeeds in complying with the regulations and successfully comes through the relevant audits. In other words, employees recognize that they get more deeply involved if they are financially rewarded.

\section{Factors that hold companies back from environmental commitments}

\section{Employers}

The expenditure that companies must face to adapt to environmental regulations and to incorporate environmentally friendly upgrades in the production processes is the major obstacle to undertake environmental measures and make more commitment in that direction. The analysis of the in-depth interviews shows that for some companies it is impossible to assume some of the investments involved in the measures that might reduce their environmental impact. Moreover, most of the employers who participated feel that with this expense they lose competitiveness.

Although, it is true that the expenditure is a factor that affects both large and small companies, certain differences can be appreciated depending on the size of the company. In this respect, it appears that small and medium-sized enterprises find it harder to face the challenge posed by environmental commitment. According to those interviewed, other factors that have an adverse effect on the environmental commitment of companies (notably large ones) are:

1. Differences in the legislation in force in the various Autonomous Regions.

2. Too much bureaucracy.

3. The reactive nature of Spanish businesses.

4. And for small and medium-sized companies:

5. Lack of knowledge about the legislation.

6. No training, information or employees with environmental expertise.

No subsidies.

The employers interviewed believe that small and medium-sized companies face more obstacles, all directly or indirectly related to economic factors.

\section{Employees}

Employees also believe that one of the main factors restricting the environmental commitment of businesses is the high cost of the investments needed to take environmental measures. The general view is that companies cut back on all types of expenses, and just limit themselves to complying with the law.

In the case of small companies, the investment problem is more serious, and lack of economic and human resources, as well as time, are pointed out. In some instances, the economic cost of environmental adaptation is magnified to the extent that it is believed 
that it may lead to the company closing down, particularly if it is a small business. Moreover, employees think that the laws are lax, which, in their opinion, reduces the chances of possible improvement given that businesses simply keep to compliance with the law.

Employees think that the size of a business has an effect on its degree of environmental involvement. Large companies take more environment-related measures and initiatives than the small ones, because they have more resources. In general, the participants believe that there is a certain lack of control and vigilance on the part of the government. The inspection and denouncement system initially implemented to put pressure on companies and force them to get involved is seen by our participants as unviable. The majority of the employees interviewed do not believe the system is feasible. Moreover, they are afraid of using it because it may endanger the survival of the company and, therefore, the jobs that go with it, which for them is the main issue.

Employees see lack of commitment by the population, users, and the government as a problem and an obstacle for companies to get environmentally involved. On the whole, they agree that the lack of awareness on the part of society and workers is strategically used by employers to inhibit employees who try to get involved in these matters. They also say that this lack of awareness and commitment on the part of employees is mainly due to their prioritizing their jobs, since in some cases keeping jobs is incompatible with measures to protect the environment. Furthermore, there is not enough information and training, a shortage of economic and human resources, and within the business organizational structure and job competencies, there is a lack of procedures to implement "good practices" and correctly carry out tasks such as separating waste and depositing it in the places provided for the purpose. The employees insist again and again that, in their opinion, the factor that most restricts the commitment of employees is the fear that denouncement can lead to the company closing down, with the ensuing loss of jobs.

The last limiting factor discussed relates directly to the activity developed by some companies. It is stressed that there are circumstances that involve environmental damage that are virtually unavoidable and that they are very difficult to address due to the technical aspects involved.

\section{Strengths and weakness of industrial environmental policies}

\section{Employers}

As a rule, the results obtained concerning strengths and weaknesses of the environmental policies of industries show certain differences of opinion. In most cases, references to strong and weak points in environmental matters appear to be conditioned by the experience the company has from within its own industrial sector.

The only perception on which there appears to be agreement is the lack of procedures to use resources reasonably, since all the employers surveyed state that they waste resources such as water, energy and raw materials.

As for the control of emissions, dumping, and waste, we have found clearly differing opinions depending on the size of the employer's company. The view among large businesses is that progress has been made in the control of polluting emissions, dumping, and waste treatment, whereas in small and medium-sized companies they believe these are the issues where their environmental policies fail the most.

Pollution of soil, ecosystems and landscapes is seen as a problem only by large companies, but, at the same time, it is felt to be one of the aspects on which the productive activities of companies have the least impact.

The main difference of opinion as expressed by representatives for both small and large businesses is that the latter have clearly identified their strengths and weaknesses in relation to the environment, whereas the employers of small companies point out that they do not know what their situation is with respect to environmental matters, and they tend to form an opinion based on their personal experience as citizens.

\section{Employees}

The employees within our discussion group think that small businesses cannot do much for the environment, that their situation is limited, and that the environmental issue is a problem pertaining to politics and large companies. They point out, however, that environmental improvements are being implemented, albeit slowly, thanks to initiatives and/or fines by the relevant authority. The initiatives taken by small and mediumsized companies are practically limited to the recycling of the products that they use regularly.

The most common initiatives taken by many mediumsized and large companies also relate to recycling and selective collection of waste. Likewise, most of the employees interviewed affirm that other very specific production-line aspects related to dumping or energy consumption have improved and are still improving.

In the case of highly polluting industries, important measures are beginning to be taken to control emissions, dumping, and waste. According to the employees, old practices have been corrected and this is valued positively; they even think that the investments made can be profitable for companies. Their perception is that companies have already planned other measures to control pollution in the future, though these measures may be slow in coming. However, the employees believe that these corrective and control measures have begun out of the necessity to apply 
recent regulations.

\section{Perceptions about environmental training}

\section{Employers}

Implementation and development of environmental training appears to have emerged from the training in matters of work related risk prevention. In this respect, it must be said that, when analysing the interviews, we found significant differences related to the size of the business.

The employers in small and medium-sized companies state that they have not implemented environmental training programmes, but they have implemented work related risk prevention training. Nonetheless, their attitude towards environmental training is positive, that is, they are aware that it is necessary and they are willing to learn more about the environmental training on offer, being particularly motivated by health risks.

By contrast, it is the large companies that appear to be making a greater effort in training, which is not surprising in view of the fact that they have more human and economic resources and they are legally obliged to implement this type action.

According to the employers of large companies, training in environmental matters is positively received by the different agents involved: senior management, middle managers and workers, and it seems that workers are the ones that most welcome this training. The fact that the lowest levels within the business organization are the most receptive may be explained by the fact that most of these employees work with highly toxic products and, as a result, they are more interested in knowing how to handle these products correctly so as to prevent damage to their health and the environment.

According to the employers, training is usually specific (adapted), depending on the targeted group, so there are work related risk prevention training programmes aimed at executives, middle managers, and workers, and their contents are clearly differentiated.

Nevertheless, there is still a lot of work to be done. In this respect, they stress the need to adapt to real training needs and implement a pedagogical training/ targeted group adjustment, so that the training process is more participative (the exchange of opinions, experiences, common conclusions, etc.).

According to the people responsible for environmental issues in the companies surveyed, another aspect that must be taken into account from the pedagogical standpoint is how to change the behaviour of workers, pointing to the fact that it takes time to change the way in which things are done. In general, all the employers think that the time element involved is a restraint when it comes to investing in training, and something to take into consideration when designing training programmes.

In order to minimize the problems created by training, the employers insist on how important it is to argue the need for training, connecting it to health risks and specific jobs, and creating awareness within the company's top management so that production plans include the time required for training.

\section{Employees}

All the participants agree that they lack training and, therefore, knowledge of environmental issues, yet what they most complain about is that their companies do not actually get involved in the process of informing and training. They do not know if there are technicians or other qualified workers specifically trained in environmental matters, but they sense that there are specialized departments.

Generally speaking, the employees interviewed do not feel they are qualified to address environmental issues, and in all cases they blame their lack of environmental training on the fact that it is not promoted, unlike what happens with work related risk prevention, to which some give priority.

\section{Perceptions regarding employee participation in environmental matters}

\section{Employers}

When the employers were asked if they know about the regulations on employee participation in environmental policies, we found once again clearly differing opinions depending on the size of the company: the people in charge of environmental departments in large companies know the regulations, whereas there appears to be a widespread lack of knowledge among the people managing small companies.

Although, all the interviewed employers agree on the relevance of employees' participation in the design and planning of environment-related measures, the truth is that none of them believes that this participation is promoted in actual practice. Their perception is that companies that establish space for participation do it mechanically, without truly being aware of the advantages.

The representatives of large companies emphasize that, although the top management of large companies is aware of regulations on participation, it is necessary that employees be aware, too. In their judgment, this change of attitude is still to come. They believe that, among employees, there is a general lack of awareness that their participation is possible and necessary.

\section{Employees}

The perception is that employees do not know about the existence and implementation of integral 
environmental management policies and systems in their companies, nor about means of participation. Only one of the participants knew for certain that his company has implemented the ISO 14001 Environmental Management System. From what was said in the groups, it is likely that other companies are beginning to take management measures. Therefore, we may be facing two different situations: there are few companies which have started to implement integral management systems, while at the same time employers and officers do not provide employees with information, let alone give them the opportunity to participate in environmental policies. Despite the fact that likely integral environmental management systems are not in place, some employees mentioned that there are teams of employees and middle managers in charge of some environmental tasks, and they express some mistrust in this respect.

\section{Factors promoting employee participation in the environmental policy of a business}

Finally, we will look at some of the suggestions putforward by the representatives of the companies surveyed in order to promote employees' participation in environmental matters.

Fluid and consistent communication: the participants recognize that sometimes employees are exposed to inconsistent messages within the company. This lack of consistency in communication discourages employees from participation and involvement in measures to improve environmental policies.

Feedback: participation by employees must have a response by the company. According to the interviewed employees, suggestion boxes or formal spaces for participation is not enough. It is also necessary for employees to feel that their participation is important to the company and that the company responds to their questions and doubts.

Transversal aspects of environmental measures: measures aimed at implementing good practices in environmental matters compete with other types of rules within organizations, so they cannot always be applied. The participants believe that environmental policy must be applied across all the sections and activities of the company, and it must not conflict with other internal rules.

Effects on other areas: awareness that good practices not only have a positive effect on the environment or on work health, but also on the health of the whole community, may encourage employees to participate actively in the environmental policies of their companies.

\section{Conclusion}

The conclusions set out below arise from the analysis of the results of the survey carried out among the representatives of employers in environmental matters and the employee discussion groups.

Environmental awareness: There is an agreement that the level of environmental concern and awareness regarding the serious nature of production-related activities has gradually increased among employers and employees in recent years (particularly since the 1990s). The changing attitude within companies reflects the changes in attitude of our society as a whole.

All the participants feel that a diffuse but real and extensive environmental culture has spread across the population and that employees are more and more concerned about their environmental responsibility visà-vis society. The analysis of their discourse and responses clearly shows that cultural and political changes in neighbouring countries in recent years has affected our country, where the population, on the basis of its own experience, has changed notably with regard to their attitude toward the environment. Therefore, the cultural change in the world of businesses, and particularly among employees, is the result of a variety of concomitant factors.

Advances in the matter are clearly different depending on the size of the business. Development is still slow in small and medium-sized companies, among employers as well as employees. The latter are aware of the problems but they think that they cannot do much for their companies.

The level of environmental information and knowledge among employees is still low, so their understanding of the extent of the environmental issue is also relatively low.

Environmental commitment: Corporate image and legislation appear to be the determining factors for companies to become environmentally committed. The representatives of both employers and employees seem to agree on this point. The majority of the employees think that the fear of fines is the main reason for business management to take measures. This result is consistent with a study carried out by Junquera (1997) on companies in Asturias. That study concluded that the two major reasons for the implementation of environmental policies are improving the corporate image and the need to comply with the legislation.

Furthermore, the employees believe that the fear that an environmentally adverse image may result in the company losing market share is a stronger reason for the company to acquire environmental commitments than the one derived from the assumption of environmental commitment associated with corporate social responsibility. This factor is more pronounced in the case of businesses whose activity is closely linked to their public image, since, for these businesses, their 
image of being connected to environmental quality is a fundamental marketing tool.

The analysis of the interviews and discussions also shows that the factors restraining the environmental commitment of businesses are principally expenditure and the lack of information and training. The employers stress the former while the employees emphasize the latter. As yet, there is no business culture directly linking stability of business projects to the environmental sustainability of activities. For this reason, most employers do not think of environmental expenditure as an investment for the future, but as a new cost that negatively affects their profits.

Among employees, the idea of the need for environmentally sustainable work which guarantees employment in the middle and the long term has not yet developed and spread sufficiently. Many employees feel that fines imposed on companies are threats to their jobs. The small companies also point out as negative factors the lack of government subsidies and information.

Strengths and weaknesses of business activities and the environment: Irresponsible use of resources such as raw materials, water, and energy are weaknesses identified by both employers and employees. Employers point out that large companies have started to take saving and efficiency measures, seeking to reduce their costs; and employees stress that the control of emissions and dumping can be improved and polluting impacts be reduced.

Environmental training: Employers and employees say that, when it comes to designing training programmes, the difference between the various internal sectors of a company must be taken into consideration so that contents can be adapted to the peculiarities of each group. According to the survey carried out, all participants agree that arguments must meet the concerns of each sector (economic and image in the case of management, and work-related health and environmental impact on the community in the case of employees). Available time is a key factor to keep in mind.

Training, therefore, is another key element in order for environmental issues to be dealt with efficiently. This is not only because it is another significant element of the commitment by top management, but also because, thanks to education and training, employees are more aware of the need to control environmental impacts, and consequently they become more receptive to changes. The company must establish procedures to identify needs and provide all its employees with the right training. It will be necessary for all the staff, at all levels, to receive general training which emphasizes the relevance of the organization's environmental commitment, the environmental impacts and risks associated with its specific activities, the measures implemented, and the advantages expected to arise from them, etc. It must be borne in mind that if employees do not understand the effects of their own actions, it will be difficult for the company to succeed in terms of its environmental behaviour. Together with general training, it may be interesting to have specific training for each job when deficiencies are detected.

Participation of employees in environmental matters: Participation by employees in the environmental policies of their companies appears to be rather low. For this reason, the participants emphasize the need for companies to implement an internally consistent communication policy, and to tell their employees how important their participation is.

On the basis of the aforementioned, it can be inferred that the environmental management of a company is a response to corporate image criteria, compliance with legislation, and cost reduction rather than a genuinely felt commitment to the environment. However, this assertion is limited by the method applied to this study and will need to be verified through future quantitative research.

Therefore, working on all the factors mentioned above will enable companies to improve their management. Commitment is required from the different parties involved, that is, companies, employees, and the government, in such a way that each pressure group can feel its needs fulfilled. In this respect, the government must legislate proactively, so as to get employers involved; promote environment-friendly attitudes; and penalize actions damaging the environment. Employees need to know and internalize their real capacity to change business attitudes, given the fact that they are a pressure group. Their demands for more environmental training and information will make change possible. Finally, the managing group will have to adapt and thus achieve the right corporate image that will ultimately help to achieve business objectives.

\section{REFERENCES}

Bansal P, Roth K (2000). "Why companies go green: A model of ecological responsiveness" Acad. Manage. J., 43(4): 717-736

Freeman RE (1984). Strategic management: a stakeholder approach. Boston: Pitman.

Fuentes F (1995). "La legislación española (1972-1978-1985) y comunitaria. La incidencia de España en la CEE en el derecho ambiental español", en Instituto Nacional De Consumo.

Govindarajulu N, Daily BF (2004) "Motivating employees for environmental improvement". Ind. Manage., 104(4): 364-372.

Hoffman A (1993). "Teaching old dogs, new tricks: Creating incentives for industry to adopt pollution prevention". Pollution Prevention Review. Winter, 1992/93.

Hunt D, Johnson C (2000). Sistemas de Gestión Medioambiental. Ed. McGraw-Hill.

Junquera B (1997). "Actitud de las empresas ante los problemas medioambientales. El caso de Asturias". Economía Industrial. 318:165-171

Llorente JL (2004). "La evolución de los sistemas de gestión de salud y seguridad: marco legal y tendencias de la prevención de riesgos laborales" Quilitas hodie, Excelencia, desarrollo sostenible e innovación, 98: 48-50.

Madsen $H$, Ulhoi JP (2001). "Integrating environmental and stakeholder management”. Bus. Strateg. Environ., 10 (2): 77-88. 
Martinez V, Lucas A (2002): La construcción de las organizaciones: La cultura de la empresa. UNED. Madrid.

Olano I, Ferrer M (2006) La participación de los trabajadores en la protección del medio ambiente en el centro de trabajo. ISTAS. Madrid.

Shrivasta P (1994). "Castrated environment: Greening organizational studies”. Organ. Stud., 15: 705-726.
Theyel G (2000) "Management practices for environmental innovation and performance". Int. J. Oper. Prod., 2(2). 